\title{
Antonin Artaud, Artaud le Mômo, Ci-git e altre poesie
}

\section{Alessandro Giarda}

\section{(2) OpenEdition}

\section{Journals}

\section{Edizione digitale}

URL: http://journals.openedition.org/studifrancesi/35157

DOI: 10.4000/studifrancesi.35157

ISSN: 2427-5856

\section{Editore}

Rosenberg \& Sellier

\section{Edizione cartacea}

Data di pubblicazione: 1 novembre 2005

Paginazione: 449

ISSN: 0039-2944

\section{Notizia bibliografica digitale}

Alessandro Giarda, «Antonin Artaud, Artaud le Mômo, Ci-gît e altre poesie», Studi Francesi [Online], 146 (XLIX | II) | 2005, online dal 30 novembre 2015, consultato il 18 avril 2021. URL: http://

journals.openedition.org/studifrancesi/35157 ; DOI: https://doi.org/10.4000/studifrancesi.35157

Questo documento è stato generato automaticamente il 18 avril 2021.

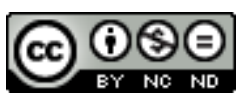

Studi Francesi è distribuita con Licenza Creative Commons Attribuzione - Non commerciale - Non opere derivate 4.0 Internazionale. 


\title{
Antonin Artaud, Artaud le Mômo, Ci- git e altre poesie
}

\author{
Alessandro Giarda
}

\section{NOTIZIA}

ANTONIN ARTAUD, Artaud le Mômo, Ci-gît e altre poesie, a cura di Giorgia BONGIORNo, Torino,

Einaudi, 2003, pp. 240.

1 Viene qui proposta una breve, ma non per questo meno significativa, antologia delle opere poetiche di Antonin Artaud. Stabilire con certezza all'interno dalla sterminata produzione di questo autore $\mathrm{i}$ confini tra cià che è poesia e ciò che non lo è, costituisce già di per sé, un'ardua impresa. Ci si trova d'altronde di fronte al paradosso di un grande poeta che confessa di avere «l'odio profondo per la poesia» e, ciononostante, ogni suo scritto risulta impregnato del ritmo e della musicalità del verso. Questa edizione di pone l'obiettivo di fornire una rapida visione d'insieme del percorso creativo di Artaud. Nella traduzione del pittore e scrittore Emilio Tadini e di sua moglie Antonia, accompagnata dal testo francese a fronte, si passa dai primi lavori letterari fino alle opere maggiori della maturità. Vengono inizialmente presentate alcune acerbe composizioni giovanili influenzate dalle letture di Baudelaire, Nerval, Poe, insieme ad estratti dalla prima raccolta Tric Trac du Ciel risalente ai primissimi anni Venti e ancora immersi in un clima tardosimbolista venato di elementi esoterici. Tre poesie tra cui Invocation à la momie rappresentano il periodo surrealista, mentre il frammento dell'incompiuta prosa poetica Vie et mort de Satan le feu è la sola testimonianza della face metafisica degli anni Trenta. I restanti due terzi della raccolta sono riservati agli scritti materialisti che seguono il ritorno di Artaud a Parigi dopo l'uscita dal manicomio di Rodez. I due grandi poemi che danno il titolo alla raccolta, ovvero Artaud le Mômo e Cigit risalgono entrambi al 1947 e costituiscono un esempio fulminante di quella «scrittura orale» sviluppata da Artaud, destinata ad investire direttamente il corpo e i nervi, con il suo andamento fortemente cadenzato e con l'impiego di sonorità dure e stridenti. Sono questi, insieme ai finali Interjactions e Cogne et foutre (provenienti da 
Suppôts et Supplications), tsti violenti, osceni al limite della blasfemia, documenti di quella che Tadini definisce "una vita sconvolta e sconvolgente»; testi scritti da un mômo termine che nell'argot marsigliese indica di volta in volta il folle, il semplice, il bambino, ma che, come suggerisce Paule Thévenin, è riferibile pure a Momos il dio dello scherzo e della beffa «deliri lucidissimi traboccanti di humour nero volti ad attaccate tutti i sistemi che tendono ad occultare e doppiare la realtà, volutamente illeggibili e incomprensibili «tal[i] che le formazioni vischiose / dell'essere / non possano più inforfarl[i] da vicino» come attesa d'altronde il largo impiego di glossolalie, esplosioni sillabiche pre-verbali tipiche degli infanti e degli schizofrenici, la cui comparsa equivale, all'interno del discorso, ad una indicibile ed immediatamente trasmissibile scarica pulsionale capace di bucare a detta di Gilles Deleuze la superficie del senso.

2 Accompagnata da un vasto e assai dettagliato apparato di note e da una puntuale introduzione di Giorgia Bongiorno dove viene fatto il punto sulle più recenti interpretazioni critiche intorno all'opera di Artaud, questo volume, a nostro avviso, si presta molto bene ad essere indicato come ottimo strumento soprattutto per coloro che si accingono ad avventurarsi per la prima volta nel crudele universo poetico di questo «suppliziato del linguaggio». 